\title{
CARTESIANO, À SUA MANEIRA: ENTRE OS EMBUSTES E CAMUFLAGENS DE SILVIANO SANTIAGO ${ }^{1}$
}

\section{CARTESIAN, IN HIS OWN WAY: BETWEEN THE SCAMS AND CAMOUFLAGES OF SILVIANO SANTIAGO}

\author{
Maria Elisa Rodrigues Moreira \\ Universidade Federal de Mato Grosso \\ Cuiabá, Mato Grosso, Brasil
}

\begin{abstract}
Resumo: Escritor e intelectual relevante na cena literária não apenas brasileira, Silviano Santiago é autor de uma obra que se caracteriza pela constante burla dos limites entre os gêneros literários, tais como a biografia, a autobiografia, as memórias, os ensaios, a ficção. Neste artigo, recorrendo às reflexões de Cássio Hissa acerca da noção de "fronteira" e às de JeanFrançois Lyotard e Eneida Souza sobre "saberes narrativos", proponho uma breve análise do livro $O$ falso mentiroso: memórias (2004), no qual Santiago, num processo de "contaminação" e "hibridização", articula ensaio, crítica e ficção para refletir sobre questões caras à sua produção.
\end{abstract}

Palavras-chave: Hibridismo. Fronteira. Ficção. Ensaio. Silviano Santiago.

\begin{abstract}
Known as a fiction writer and an important intelectual in the brazilian literary scene as well as in the foreign scene, Silviano Santiago is an author whose works are characterized by a persistent mockery of the limits among the literary genres, like the biography, the autobiography, the memoirs, the essays and the fictions. In this paper, resorting to the Cassio Hissa's theories about the notions of "borders", as well as the Jean-François Lyotard and Eneida Souza's reflections about "narrative knowledges", I propose a brief analysis about the book " $O$ falso mentiroso: memórias" [The False Liar: Memories] (2004), in which Santiago, into a "contamination" and "hybridization" process, links essay, critic and fiction to thinking better about the most important questions in his literary production.
\end{abstract}

Keywords: Hybridism. Border. Fiction. Essay. Silviano Santiago.

\footnotetext{
${ }^{1}$ Uma versão reduzida deste texto foi apresentada no IV Congreso Internacional Cuestiones Críticas, ocorrido em Rosário, Argentina, em 2015.
} 
Inserir alguma coisa [...] noutra diferente [...] significa relativizar o poder e os limites de ambas, $e$ significa também admitir outras perspectivas de trabalho para o escritor e oferecer-lhe outras facetas de percepção do objeto literário, que se tornou diferenciado e hibrido.

Silviano Santiago

Diferenciada e híbrida: assim pode ser caracterizada a produção do crítico e ficcionista mineiro Silviano Santiago, cuja obra se distingue por uma persistente burla dos limites. Por ela transitam biografia, autobiografia, memórias, ensaio, romance, de modo que teoria e ficção se movem continuamente, sem fixarem-se a espaços pré-determinados, habitando as margens e as fronteiras entre os gêneros narrativos. Em continuidade ao trecho aqui utilizado como epígrafe, inserido em um texto no qual reflete sobre o "ofício de criar", Santiago afirma: "são as margens em constante contaminação que se adiantam como lugar de trabalho do escritor e de resolução dos problemas da escrita criativa" (SANTIAGO, 2008a, p. 174, grifos do autor). É, pois, a tentar mapear esse território híbrido e multifacetado que este texto se dedicará, tomando por eixo as formas de articulação entre ensaio, crítica e ficção que se nos apresentam no livro $O$ falso mentiroso: memórias (2004).

O hibridismo da produção de Silviano Santiago é um traço comum de parte significativa da literatura contemporânea e faz com que esta, muitas vezes, coloque-se como um grande desafio à teoria e à crítica, que se deparam com textos inclassificáveis, os quais, operando por deslocamentos, metamorfoseiam-se continuamente e transbordam os limites dos discursos ficcional e ensaístico, solicitando leituras que sejam, elas próprias, diferenciadas, de modo a impulsionar a movimentação das fronteiras dos conhecimentos. A fronteira aparece, nessa perspectiva, como um importante operador de leitura para se refletir sobre a produção literária contemporânea, pois, se por um lado, ela nos coloca diante da desordem da escrita, do saber e do pensamento, por outro ela abre enriquecedoras perspectivas: escrever na fronteira e sobre a fronteira é aceitar um risco e, ao mesmo tempo, dele se valer como elemento produtivo (HISSA, 2006).

A imagem conceitual da fronteira com a qual oriento as reflexões aqui apresentadas, portanto, constitui-se a partir das ideias de abertura, contato e integração, as quais acredito serem caras aos estudos literários contemporâneos voltados a produções que, como as de Silviano Santiago, parecem a todo o tempo questionar o que as limita, distancia e separa: é sob o signo da fronteira que se vai instituir o diálogo proposto entre a ficção e a teoria, diálogo este que, no texto santiaguino, provoca um deslocamento contínuo entre uma e outra, colocando em questão os próprios estatutos teórico e ficcional, a distinção entre o que caracteriza a prática da escrita criativa e a reflexão que se constrói sobre ela.

O falso mentiroso: memórias, é, assim, tomado como um texto fronteiriço, no qual reflexões críticas e teóricas caras a Silviano Santiago são embutidas e camufladas no corpo da ficção, transformadas em argumentos narrativos de um texto com múltiplas e complexas camadas de sentido, as quais permitem que 
nelas se adentre por variados caminhos, que com elas e entre elas se estabeleçam distintas conexões.

\section{Caminhos da "ficção teórica": literatura e pensamento}

A aproximação entre o "exercício intelectual" e a "literatura" não é um fato novo, mostrando-se como uma estratégia narrativa à qual diversos autores já recorreram em suas obras. Talvez um dos casos mais emblemáticos dessa perspectiva seja o do "Pierre Menard, autor do Quixote", de Jorge Luis Borges (2007), texto apresentado como um ensaio de crítica literária no qual se tece uma reflexão engenhosa sobre os processos de escrita, leitura e tradução e que integra o volume Ficções - o que, por si só, já desloca e coloca em trânsito os espaços tradicionalmente dedicados ao pensamento e à imaginação. Nessa narrativa, Borges nos apresenta a Pierre Menard, um romancista e crítico francês que deixou certa "obra visível" ("a relação de escritos que lhe atribuo pode não ser muito divertida, mas não é arbitrária; traça um diagrama de sua história mental...", afirma o autor no Prólogo ao livro) mas cujo maior feito é o que se encontra em sua outra obra, "a subterrânea, a interminavelmente heroica, a sem-par": essa obra consiste na escrita, por Menard, de dois capítulos completos e um inconcluso de Dom Quixote, os quais coincidiam palavra por palavra com a obra de Cervantes. O texto de Borges teria como "objeto primordial" justificar o disparate de tal empreitada. O processo de hibridação entre teoria e ficção levado a cabo por Borges, o deslocamento que provoca dos códigos do discurso - nesse caso, via o personagem Menard -, é explicitado numa afirmação atribuída pelo narrador ao próprio Menard: "Pensar, analisar, inventar [escreveu-me também] não são atos anômalos, são a respiração normal da inteligência". (BORGES, 2007, p. 44)

Essa conjunção entre a teoria e a ficção, o transitar entre as fronteiras do "pensar" e do "inventar", uma das características marcantes da obra de Borges, pode ser observada com incidência cada vez maior na literatura a partir de meados do século XX, levando-nos a tomar esses textos fronteiriços como formas de uma poética que se constitui de maneira articulada com as importantes mudanças ocorridas nas correntes teóricas do período, as quais tornam o campo da teoria e do fazer literários mais ampliados e porosos às reflexões provindas de áreas afins como as artes, a filosofia e a história, por exemplo.

Dentre essas correntes, interessam-nos mais diretamente os estudos que procuram aprofundar a reflexão sobre o saber narrativo e o teor teórico da ficção, discutindo as fronteiras entre arte e ciência. $\mathrm{O}$ saber narrativo retira de cena exigências típicas do saber científico - em especial, a demonstração e a verificação - e insiste na irredutibilidade do que há de plural no mundo (LYOTARD, 2008; SOUZA, 2004): absorvida por diversos campos do saber, a narrativa instaura novas possibilidades investigativas na medida em que altera o lugar no qual se produz o conhecimento e a relação entre sujeito e objeto de investigação. Segundo Jean-François Lyotard (2008, p. 38), o saber narrativo não exclui de sua tessitura a multiplicidade de linguagens, a complexidade da realidade e as contradições e buracos do processo de produção de conhecimento; 
ao contrário, seus principais elementos são justamente a incorporação desses paradoxos e vazios, seu caráter inacabado e inconclusivo e a impossibilidade de verificação que o permeia.

Eneida Maria de Souza, por seu turno, vale-se da expressão "reflexão narrativa" e retoma o comentário de Ricardo Piglia sobre a cena biográfica de Nietzsche recriando uma situação de Dostoiévski: Piglia afirma que um dos mais famosos episódios da história da filosofia, aquele no qual Nietzsche depara-se com um cavalo sendo cruelmente açoitado e o abraça e beija chorando, é um "efeito do poder da literatura", pois é uma "repetição literal" de um trecho de Crime e Castigo. Segundo a autora, "ao declarar, a partir dessa cena, o fim da filosofia e o início da loucura de Nietzsche, o escritor argentino não só inscreve o poder de mimetização da vida em relação à literatura, mas reforça o teor ficcional da teoria assinada pelo filósofo" (SOUZA, 2004, p. 59, grifos meus). Se a cena em questão ressalta o "teor ficcional da teoria", remeto a outro exemplo trazido pela autora para propor também nesse jogo de fronteiras o movimento diametralmente oposto, aquele em que se ressalta o "teor teórico da ficção": Eneida Souza analisa a abordagem do mito da Medusa feita por Italo Calvino em suas Seis propostas para o próximo milênio, afirmando que ali o escritor italiano "constrói uma narrativa que se mescla à sua intenção de teorizar a poesia" (SOUZA, 2004, p. 61).

Esse movimento de mistura constante, em que a relação teoria-ficção não apresenta qualquer sentido de ascendência de uma sobre a outra, inevitavelmente coloca em questão também o "teor político da ficção", já que desloca a literatura e a imaginação para um lugar de produção ativa do exercício intelectual. A consciência desses escritores acerca das possibilidades de um saber narrativo proporcionado pela literatura e o desejo de sua potencialização fazem do espessamento dos limites entre reflexão e ficção uma possível estratégia para tecer em suas obras ligações entre as múltiplas maneiras encontradas por eles para se intervir no mundo em que vivem. Ao trazerem para o corpo da ficção suas reflexões, eles as transformam em argumentos narrativos e ampliam o aspecto fronteiriço de seus textos.

Assim, a tessitura narrativa de obras literárias como as de Borges, Italo Calvino, Ricardo Piglia, Gonçalo M. Tavares, J. M. Coetzee, Enrique Vila-Matas e, no caso brasileiro, Silviano Santiago - apenas para mencionar alguns nomes comumente associados a essa perspectiva - faz com que o espaço da teoria seja invadido e transbordado pelo discurso da margem, da fronteira, do que não teria a propriedade e o rigor para aí adentrar - a ficção. Por meio desse movimento que violenta a teoria, os escritores reafirmam, no entanto, seu compromisso com ela, garantindo-a como espaço de travessias várias, como uma teoria-ficção ou um ensaio-narrativa (BHABHA, 2007, p. 54-55).

\section{As falsas mentiras da narrativa-ensaio de Silviano Santiago}

É nesse panorama crítico-teórico que se insere a obra de Silviano Santiago, professor, crítico e escritor nascido na cidade de Formiga, Minas Gerais, em 
1936, e que tem sua própria trajetória marcada pelo deslocamento: ${ }^{2}$ transferiu-se para Belo Horizonte em 1948 para dar continuidade a seus estudos e, na capital mineira, começou a frequentar o Centro de Estudos Cinematográficos (CEC) e os círculos artísticos e literários de então. No final dos anos 1950 ingressou no Curso de Letras da Universidade de Minas Gerais e, já em 1960, publicou seus primeiros textos literários. Nesse mesmo ano mudou-se para o Rio de Janeiro, conseguindo em seguida uma bolsa do governo francês para cursar o doutorado na Universidade de Sorbonne. Após atuar como professor visitante em universidades de diversos países, tornou-se professor e pesquisador em universidades cariocas, contando hoje com uma ampla e relevante produção intelectual, ficcional ou não, internacionalmente reconhecida.

Sua produção se marca por um processo de "contaminação" e "hibridização", para retomarmos termos do próprio autor (SANTIAGO, 2008a, 2008b), que acaba por diluir os limites entre os territórios da ficção, da teoria e da crítica: o romance Em liberdade, por exemplo, publicado em 1981, apresenta ao leitor um "falso diário" do escritor brasileiro Graciliano Ramos e dialoga ainda com outros momentos da história brasileira, propondo uma reflexão sobre os limites entre realidade e ficção, questão que se desdobra posteriormente nos livros O falso mentiroso: memórias (2004), Histórias mal contadas (2005) e Mil rosas roubadas: romance (2014), obras em que a prosa autoficcional acrescenta ao duo real/ficcional a questão da memória e da biografia.

São múltiplos os caminhos pelos quais se pode abordar $O$ falso mentiroso: memórias, obra à qual se dedica este texto (RIBEIRO, 2006; SILVA, 2008; FARIAS, 2013), dentre os quais ressaltarei a relação verdade/mentira/ficção e a ideia de "burla" que atravessa toda a narrativa a partir da reflexão sobre o nascimento do narrador: como afirma a pesquisadora Valéria da Silva (2008, p. 172), retomando uma frase do próprio romance, "a ideia de "posso estar mentindo, posso estar dizendo a verdade' é uma constante durante todo o livro". É no próprio título do livro que começa a se delinear esse problema, por meio do deslocamento entre gêneros e da problematização desse deslocamento: a expressão "o falso mentiroso" remete ao paradoxo atribuído a Euclides de Mileto, o qual aponta para a situação paradoxal que se cria quando alguém afirma mentir - se a afirmação "eu minto" é verdadeira e a pessoa pode ser tomada por mentirosa, teríamos aí uma situação de verdade; se, por outro lado, aquela é uma mentira, ou seja, se a pessoa diz a verdade, ela incorre em falsidade ao afirmar o contrário. Como qualquer paradoxo, esse funciona como um elemento de complicação para o pensamento, uma vez que não é possível que se chegue a uma conclusão relativa a ele.

O livro de Silviano, não bastasse trazer essa perspectiva paradoxal ao título, ainda o envolve pelo subtítulo "memórias", remetendo a um gênero

\footnotetext{
${ }^{2}$ Esse vínculo entre o deslocamento e a produção artística de Silviano Santiago é abordado, pelo próprio autor, em "A experiência radical": "Esses constantes deslocamentos me levaram a ter certo prazer em trabalhar com formas de gênero misturadas. Eu posso escrever, por exemplo, romances, ensaios e poemas. Posso, inclusive, desenvolver vários gêneros em uma só obra." (SANTIAGO, 2014, p. 103).
} 
literário já clássico e, assim, amplificando a dúvida sobre a relação entre verdade e mentira que ali se anuncia e colocando em xeque toda a narrativa, que passa a ser lida sob a seguinte questão: como se colocar frente às memórias de um falso mentiroso? Essa "brincadeira" com o título atinge mais que apenas o livro em questão, e coloca em suspensão o próprio par memória/ficção e as características normalmente atribuídas a cada um de seus elementos, vinculando-se a reflexões caras aos estudos literários, que marcam sua presença nos textos críticos e ensaísticos de Silviano Santiago: as relações entre a biografia/autobiografia e a ficção; a articulação entre a memória pessoal, a memória coletiva e os procedimentos narrativos; o posicionamento crítico frente à tradição literária, à filiação e à influência; a insuficiência dos gêneros literários e a possibilidade de espessamento de seus limites...

É, pois, sob a sombra de todas essas questões que adentramos o universo narrativo do livro, que nos apresenta as memórias desse falso mentiroso narradas por Samuel Carneiro de Souza Aguiar, que opta por começar a contar suas lembranças apontando justamente para as dúvidas que tem sobre sua origem e, portanto, sobre o próprio nome que carrega: "Caí de paraquedas entre os Carneiro, no lado materno, e entre os Souza Aguiar, no lado paterno. Samuel Carneiro de Souza Aguiar" (SANTIAGO, 2004, p. 21). A dúvida sobre a filiação perpassa todo o livro, mas nos primeiros capítulos é o objeto principal das memórias do narrador, que nos fala de sua "falsa" mãe, Dona Ana Carneiro, e de seu "falso" pai, o Dr. Eucanaã de Souza Aguiar, apresentando várias possíveis versões para seu nascimento e chegada à família Souza Aguiar. Quatro dessas versões são explicitadas ao leitor, como tais, no terceiro capítulo do livro. A primeira versão, que norteara a narrativa até o momento, indica a adoção ilegal do bebê pela família por meio de um complô mercantil realizado entre o obstetra, duas enfermeiras e os "falsos" pais:

Não sei se conto. Conto. Na minha certidão a data de nascimento não é a do meu nascimento. É a data da minha morte para os meus pais. Os verdadeiros. $\mathrm{O}$ dia do meu nascimento na certidão é o do meu renascimento na casa dos meus pais. Os falsos.

Nasci e morri aos dezenove dias de vida no berçário da maternidade. Com o nome verdadeiro. Ressuscitei-me ao deixar a tenda de oxigênio.

Tive papai e mamãe. Perdi-os no tempo e espaço. Falta o atestado de óbito.

Renasci na casa paterna. No berço do quarto de dormir do casal. Em Copacabana. Com o nome que trago.

Somos dois. Somos um. Um é cópia do outro. Gêmeos, vá lá, já que ninguém morre nesta história. (SANTIAGO, 2004, p. 48)

Essa versão coincide com as informações que até então, ainda que envoltas em uma série de contradições, vinham sendo dadas pelo narrador nos dois primeiros capítulos. A escrita marcada pelo contraditório (as frases curtas que se anulam são uma constante, como em "conto/não conto" e "somos dois/somos um", por exemplo) explicita-se no excerto a seguir, ainda relativo à primeira 
versão da filiação, no qual as "certezas" e as dúvidas se superpõem na tessitura de uma narrativa pautada pela suspeita, pela ideia de "originais" e "cópias", "verdadeiro" e "falso":

O tabelião olhou a folhinha e fez as contas. Logo em seguida consignou no livro de registros: Samuel, nascido no dia 29 de setembro de 1936, filho de Eucanaã de Souza Aguiar e de Ana Carneiro. Lá ficou consignado meu nome, seguido dos nomes dos novos pais.

Nasci (eu, o original) na maternidade, no dia 10 de setembro. Tenho certeza. O bebê original é dezenove dias mais novo do que a cópia. É o que não dizem os documentos pessoais. A certidão de idade, que tenho arquivada no escritório, diz que não minto. São eles que mentem. [...]

Problema insolúvel. Não tenho informação sobre nome e localização da maternidade. Se conseguir localizá-la, não sei por onde começar a busca. Não sei o nome da mulher que me pariu. Nem o do meu pai, que a fecundou. Não sei o nome que me foi dado lá. Não sei o nome do obstetra, da enfermeira-chefe ou o da enfermeira cegonha. Tenho uma data, 10 de setembro, e anos-luz de distância dos fatos. (Santiago, 2004, p. 49)

Mas o narrador não se contenta em deixar em suspenso a veracidade dessa versão da história por meio de sua construção linguística, aportando ainda nesse capítulo três outras possíveis versões para seu nascimento (verdadeiro) e para seu nascimento como membro da nova família (falsa). A segunda versão modifica alguns dos elementos dessa trama, tornando o Dr. Eucanaã um pai "verdadeiro" - polígamo o pai, Samuel seria filho dele com alguma de suas muitas amantes, aceito pela mãe graças ao desejo e à impossibilidade que ela tinha de engravidar. Entretanto, mesmo essa segunda versão desdobra-se em possibilidades diversas, que envolvem o desejo da mãe por um filho homem, a (possível) existência de outras filhas do pai com essas amantes, a indicação de uma determinada amiga da família como sua (possível) mãe verdadeira, como evidencia a seguinte passagem:

Papai colecionava amantes. "Fez vários filhos em outras duas antes de te entregar à esposa". Referia-se a mim, fillho único. Eram meninas as que me precederam. Ofereceu-as uma a uma a Donana.

Ana batia o pé. Desprezava as bastardas. Queria filho varão. Exigia.

Minhas irmãzinhas, quem serão elas hoje? Fica a pergunta no ar. Alguma delas será minha irmã de pai e de mãe? Outra pergunta estronda pelos ares. Por onde andarão as duas enjeitadas pela amante e pela esposa legítima? (SANTIAGO, 2004, p. 57)

As terceira e quarta versões voltam-se para o papel da mãe em toda a história. Nomeada pelo narrador como uma "mentirosa versão", a terceira história de seu nascimento circula, segundo ele, na família da mãe, como "pura maldade, fruto de inveja e cobiça das irmãs parideiras" (SANTIAGO, 2004, p. 61), e indica 
que sua mãe simulara a gravidez para a família com uma almofada, farsa "milagrosa" da qual nascera o filho:

Erro ao adjetivar a terceira versão como mentirosa. Se há (eu) original e (eu) cópia, por que não pode haver um terceiro eu? Passo de gêmeos a trigêmeos.

$\mathrm{O}$ gêmeo mais velho - filho de uma qualquer com um qualquer.

O gêmeo mais novo - filho da Senhora X com papai.

Ou será que todas as três versões são falsas? Ou será que todas as três versões não são falsas? Eu existo duas vezes. Ele existe uma terceira vez conosco. Nós existimos, os três.

Insisto. As duas primeiras versões têm de ser falsas, para que surja uma terceira? E se a mais fantasiosa das versões for a verdadeiramente verdadeira?

Verdade nada tem a ver com senso comum. Ou tem?

Senso comum nada tem a ver com bom senso. Ou tem?

Bom senso nada tem a ver com senso moral. Ou tem?

Com a palavra o meu trigêmeo, até agora silencioso. (SANTIAGO, 2004, p. 62)

Nessa versão pautada pela farsa e pelo milagre, verdade e mentira mudam de lugar com facilidade, até darem espaço ao surgimento da quarta versão, que "é triste. Triste triste", uma vez que nela "a mãe morre para salvar o filho", e o bebê, "filho órfão", acaba sendo "adotado por papai e mamãe, os falsos" (SANTIAGO, 2004, p. 65).

Essas versões, que não se solucionam e pairam sobre toda a narrativa, são ainda acrescidas, em um dos capítulos finais do livro, de uma quinta versão, na qual se juntam a todas as dúvidas em torno da veracidade da história narrada reflexões relativas ao biográfico, uma vez que as informações apontadas se identificam com a história de vida do próprio escritor: "Teria nascido em Formiga, cidade do interior de Minas Gerais. No dia 29 de setembro de 1936. Filho legítimo de Sebastião Santiago e Noêmia Farnese Santiago. A versão é tão inverossímil, que nunca quis explorá-la." (SANTIAGO, 2004, p. 180).

Com esse movimento, Silviano Santiago retoma na narrativa um tema que lhe tem sido caro, o da "literatura do eu", que envolve o que ele denomina como "quatro questões constitutivas", quais sejam: a experiência, a memória, a sinceridade e a verdade poética, sobre as quais discorre em sua "Meditação sobre o ofício de criar" (SANTIAGO, 2008a). Insistindo na falta de importância das explicações de um autor acerca de suas obras - "só ao leitor compete a tarefa da leitura", ele afirma (p. 173) -, Santiago se propõe, na conferência que originou esse texto, a apresentar ao público e com ele discutir "algumas questões abstratas que preocuparam e preocupam o escritor enquanto personalidade que reflete sobre o estatuto disso a que hoje se chama - e ele próprio passou a chamar - de autoficção" (SANTIAGO, 2008a, p. 173). Seu percurso rumo à autoficção marcou-se, segundo ele, por um "longo processo de diferenciação, preferência e contaminação" (SANTIAGO, 2008a, p. 173, grifos do autor): diferenciação que envolve os discursos autobiográfico e confessional, do qual o primeiro resulta 
como preferência indiscutível, mas tomado sob o signo da contaminação pela ficção.

Nesse percurso de hibridização, portanto, os dados autobiográficos "traduzem o contato reflexivo da subjetividade criadora com os fatos da realidade" que condicionam o autor, sendo tomados como a "força motora da criação" que se deixou "contaminar pelo conhecimento direto - atento, concentrado e ativo - do discurso ficcional da tradição ocidental" e, assim,

com a exclusão da matéria que constitui o meramente confessional, o texto híbrido, constituído pela contaminação da autobiografia pela ficção - e da ficção pela autobiografia -, marca a inserção do tosco e requintado material subjetivo meu na tradição literária ocidental e indicia a relativização por esta de seu anárquico potencial criativo (SANTIAGO, 2008a, p. 174).

É, pois, nessa fronteira entre gêneros e discursos que se situa $O$ falso mentiroso, e é das possibilidades trazidas por essa abertura ao que é distinto e que se potencializa em zonas fronteiriças que o texto se alimenta, colocando os leitores diante das memórias de um narrador que "perdeu a certeza sobre a própria verdade" e que, por isso, "constrói ficções dentro da ficção", numa trama em que "o leitor pouco pode fazer para ajudar/aconselhar o narrador" (SANTIAGO, 2010):

Por mais que ele [o leitor] tente justapor/compor as várias versões expressas pelo narrador fica sempre o gosto de cada versão não the ter sido bem contada. Não adianta, portanto, reuni-las, analisá-las em conjunto, nas semelhanças ou nas diferenças. Não há buraco, não há lacuna a ser oferecida ao leitor. O mal contado é a essência (se me permite o palavrão) da literatura ficcional (SANTIAGO, 2010).

O paradoxo, assim, persiste, e o texto continua inclassificável, pois não há como se concluir pela verdade ou mentira da narrativa desse falso mentiroso, ela é ambas as coisas, ela não é nenhuma delas. Tudo isso se torna ainda mais complexo quando se percebe que o jogo de embustes e camuflagens da narrativa não se reduz à história do nascimento de Samuel (o que já não seria pouco), mas desdobra-se e ramifica-se em outras burlas que vão se sobrepondo, como bonecas russas que se abrissem e duplicassem infinitamente. O pai de Samuel, o dr. Eucanaã, recorrente nominado como "papai, o falso", é um industrial da área da saúde que, envolvido com a produção de preservativos (e o próprio preservativo é explorado no texto santiaguino como um artifício, uma forma de burlar a concepção), usava como camuflagem a profissão de advogado: "Papai vivia de negócios honestos e escusos. De negócios camuflados. O recurso ao disfarce era coisa corriqueira no ramo de indústria a que se dedicava" (SANTIAGO, 2004, p. 102). Como filho "bastardo e pobre" da falsidade, Samuel afirma que teria de construir seu futuro apenas por sua própria vontade, o que para ele não seria difícil, já que os filhos que nascem nessas condições "Desenvolvem habilidades de embusteiro. Bolam planos de vida. Múltiplos e convincentes. Descartáveis na 
primeira lata de lixo biográfica." E o narrador continua: "O filho crescia tão impostor quanto o pai, o falso" (SANTIAGO, 2004, p. 134) e aprendeu, com a mãe, a gostar "Mais da representação do que da realidade" (SANTIAGO, 2004, p. 141). É pois, também, a "mentira" que dá o tom da vida de Samuel para além de seu nascimento duvidoso: enganou pai e mãe em relação à sua formação superior, dizendo a um que cursava Arquitetura e, à outra, que era acadêmico de Direito, quando na verdade estudava Belas-Artes. E, em seu campo profissional, optou por dedicar-se à cópia, questão que é explicitada pelo narrador em passagem que dialoga com o Pierre Menard de Borges, mencionado no princípio deste texto:

Minha obra verdadeira e subterrânea começa no dia em que elegi como modelo o gravador Oswaldo Goeldi. (...)

$\mathrm{Na}$ verdade, minha obra verdadeira e subterrânea começa no dia em que descobri como copiar Goeldi, sendo eu mesmo. (SANTIAGO, 2004, p. 184)

Não será possível, no escopo deste texto, explorar essas outras vertentes do jogo de embustes de $O$ falso mentiroso: memórias, as quais trago neste momento apenas para indicar como, por meio desse movimento, o autor reforça o ambiente de dúvida hiperbólica sobre o caráter de veracidade dessas "memórias" contadas por um falso mentiroso e, por extensão, coloca em questão o próprio gênero memorialístico, enfatizando a burla que preside a narrativa e que poderia ser sintetizada não apenas na expressão título do livro mas também na multiplicidade de possibilidades simultâneas que conformam a identidade desse narrador pósmoderno (SANTIAGO, 1989), que logo no primeiro capítulo afirma que é muitos: "Assumo. Sou cartesiano, à minha maneira, e canhoto. Ambidestro" (SANTIAGO, 2004, p. 14). O livro de Santiago parece dizer a nós, leitores, aquilo que ressalta Valéria da Silva: "isso aqui é ficção e tudo é permitido" (SILVA, 2008, p. 173). Principalmente quando se tratam das memórias de um falso mentiroso.

\section{REFERÊNCIAS}

BHABHA, Homi K. O local da cultura. Tradução de Myriam Ávila, Eliana Lourenço de Lima Reis e Gláucia Renate Gonçalves. Belo Horizonte, Ed. UFMG, 2007.

BORGES, Jorge Luis. Pierre Menard, autor do Quixote. In: BORGES, Jorge Luis. Ficções. Tradução de Davi Arrigucci Jr. São Paulo, Companhia das Letras, 2007. p. 34-45.

FARIAS, Sônia L. Ramalho de. Mímesis, memória e fingimento: O falso mentiroso, de Silviano Santiago. In: FARIAS, Sônia L. Ramalho de; PEREIRA, Kleyton Ricardo Wanderley (Org.). Mímesis e ficção. Recife, Pipa Comunicação, 2013. p. 105-155. 
HISSA, Cássio Eduardo Viana. A mobilidade das fronteiras: inserções da geografia na crise da modernidade. Belo Horizonte, Ed. UFMG, 2006.

LYOTARD, Jean-François. A condição pós-moderna. Tradução de Ricardo Corrêa Barbosa. 10. ed. Rio de Janeiro, José Olympio, 2008.

RIBEIRO, Roberto Carlos. A personagem estéril de O falso mentiroso. Letras de Hoje, Porto Alegre, v. 41, n. 3, p. 177-184, set. 2006.

SANTIAGO, Silviano. O narrador pós-moderno. In: SANTIAGO, Silviano. Nas malhas da letra. São Paulo, Companhia das Letras, 1989. p. 38-52.

SANTIAGO, Silviano. O falso mentiroso: memórias. Rio de Janeiro, Rocco, 2004.

SANTIAGO, Silviano. Meditação sobre o ofício de criar. Aletria, Belo Horizonte, n. 18, p. 173-179, jul./dez. 2008a.

SANTIAGO, Silviano. Uma literatura anfíbia. In: SANTIAGO, Silviano. $O$ cosmopolitismo do pobre: crítica literária e crítica cultural. Belo Horizonte, Ed. UFMG, 2008b. p. 64-73.

SANTIAGO, Silviano. Ana Crelia Dias entrevista Silviano Santiago. Z Cultural Revista do Programa Avançado de Cultura Contemporânea, Rio de Janeiro, ano V, n. 1, 2010. Disponível em: http://revistazcultural.pacc.ufrj.br/ana-crelia-diasentrevista-silviano-santiago/. Acesso em 20 mar. 2015.

SANTIAGO, Silviano. A experiência radical. In: GONÇALVES, José Eduardo (Org.). Ofício da palavra. Belo Horizonte, Autêntica, 2014. p. 100-113.

SILVA, Valéria da. Panis et circenses: O falso mentiroso, de Silviano Santiago. Estudos Linguísticos, São Paulo, v. 37, n. 3, p. 169-177, set./dez. 2008.

SOUZA, Eneida Maria de. Saberes narrativos. Scripta, Belo Horizonte, v. 7, n. 14, p. 56-66, jan/jun. 2004.

Maria Elisa Rodrigues Moreira ElisaRMoreira@gmail.com

Recebido em: 7 set. 2018 Aceito em: 22 nov. 2018 Publicado em: 29 dez. 2018 